\title{
Study on Melting Behavior of Polymers during Burning
}

\author{
JUN ZHANG, YONG WANG, XIAODONG LU, and JIAN YU \\ Key Laboratory of Rubber-Plastics for Ministry of Education \\ Qingdao University of Science and Technology \\ 53 Zheng Zhou Road \\ Qingdao, 266042, P.R. China
}

\begin{abstract}
The melting behavior of a number of polymers during burning, including thermoplastic and thermosetting polymers was studied by experiment and modeling. It was found that in a fire situation some thermoplastic polymers such as PP, LDPE, EVA-18 and PA6 melted significantly compared to PMMA for which the resulting melt vaporized rapidly and as a consequence there was little melt observed. On the other hand, some thermosetting resins generally did not melt or melted slightly, such as phenolic resin and epoxy resin. For the thermoplastics studied, the melting behavior affected the mass loss rates during the steady burning stage. The thermoplastics that melted significantly experienced much lower mass loss rates compared with the PMMA. This has been related to the pyrolysis mechanism of individual polymers. Generally, the polymers with a random pyrolysis process were more likely to lead to significant melting. The polymers undergoing depolymerization will lead to a rapid volatilization and therefore experienced much less melting. A numerical model for polymer burning was developed to include the melting behavior during burning. It was shown that the simulated results for the model considering melting behavior fitted in better with the cone calorimeter test results when compared to the model without considering the melting behavior.
\end{abstract}

KEYWORDS: polymer, melting behavior, modeling, burning behavior

\section{NOMENCLATURE LISTING}

\begin{tabular}{|c|c|c|c|}
\hline$c$ & specific heat $(\mathrm{J} / \mathrm{kg} \mathrm{K})$ & $Q$ & pyrolysis heat $(\mathrm{J} / \mathrm{kg})$ \\
\hline$C_{m}$ & specific heat of melting layer & $S_{m}$ & location of the melting front $(\mathrm{m})$ \\
\hline$\varepsilon$ & emissivity & $S_{t}$ & location of upper surface (m) \\
\hline$\sigma$ & $\begin{array}{l}\text { Stefan-Boltzmann constant } \\
\left(5.669 \times 10^{-8} \mathrm{~W} / \mathrm{m}^{2} \mathrm{~K}^{4}\right)\end{array}$ & $t$ & time (s) \\
\hline$h$ & $\begin{array}{l}\text { coefficient of convection heat } \\
\left(\mathrm{W} / \mathrm{m}^{2} \mathrm{~K}\right)\end{array}$ & $t_{i g}$ & time to ignition (s) \\
\hline$k$ & thermal conductivity (W/m K) & $T$ & temperature (K) \\
\hline$k_{m}$ & $\begin{array}{l}\text { thermal conductivity of the } \\
\text { melting layer }(\mathrm{W} / \mathrm{m} \mathrm{K})\end{array}$ & $T_{m}$ & melting temperature $(\mathrm{K})$ \\
\hline$L$ & thickness of original sample (m) & $T_{p}$ & pyrolysis temperature $(\mathrm{K})$ \\
\hline$\dot{m}^{\prime \prime}$ & mass flux $\left(\mathrm{g} / \mathrm{m}^{2} \mathrm{~s}\right)$ & $T_{s}$ & temperature of upper surface $(\mathrm{K})$ \\
\hline$\rho$ & density $\left(\mathrm{kg} / \mathrm{m}^{3}\right)$ & $T_{\infty}$ & environment temperature $(\mathrm{K})$ \\
\hline$\dot{q}_{e}^{\prime \prime}$ & external heat flux $\left(\mathrm{W} / \mathrm{m}^{2}\right)$ & $\mathrm{x}$ & location (m) \\
\hline
\end{tabular}




\section{INTRODUCTION}

Potential fire hazards of polymeric materials in fires are a matter of great concern. Indeed, fires involving polymers, particularly organically synthetic polymers, are characterized by a variety of specific behavior. The melting behavior is one of the most characterized behaviors for these polymers. The phenomena of melting behavior of polymers in fires are recognized commonly by the fire safety community [1]. However, there are few attempts to study it in depth. Meanwhile, most of current polymer burning models developed have not taken melting behavior into account and generally ignored its effects on the burning process [2-5]. Previous experimental investigations carried out by Zhang et al [6,7] shown that the melting behavior of thermoplastic polymers would significantly affect their burning rates when polymers with different melting behavior were tested both in a large scale test with vertically oriented sample installation and in the cone calorimeter test.

The present study investigated the melting behavior of a number of typical polymers, including thermoplastic and thermosetting polymers and attempted to identify the melting characters of the individual polymers under cone calorimeter fire conditions. Also, on the base of the experimental results, a simulation model for polymer burning was developed to include the melting behavior. The comparison between the model predictions and the experimental results was in fair agreement when the proper thermal property parameters were chosen.

\section{EXPERIMENTAL}

A number of polymers were used in the study, including PP, LDPE, EVA-18 (ethylene $82 \%+$ Vinyl-acetate 18\%), PA6, PMMA, epoxy resin and phenolic resin. All these polymers were originally bought from commercial pellet products or liquid-like components and then molded or cast into sheets using the extrusion and molding process as usual procedures. The values of density $\left(\mathrm{kg} / \mathrm{m}^{3}\right)$ for the polymers studied were measured using the Density Analyzer GT-XB320M (Gotech Co.) and are as follows: 905 for the PP, 802 for the LDPE, 900 for the EVA-18, 1095 for the PA6, 1182 for the PMMA, 1168 for the epoxy resin and 1225 for the phenolic resin. None of the polymer samples contained fillers and additives, except for a very small amount of anti-oxidants. The FTT standard cone calorimeter was used to carry out the burning tests at the external heat flux level of $50 \mathrm{~kW} / \mathrm{m}^{2}$. The sizes of each sample were $100 \mathrm{~mm}$ x $100 \mathrm{~mm}$ x $10 \mathrm{~mm}$ (length $\mathrm{x}$ width $\mathrm{x}$ thickness) for the mass loss rate measurement by the cone calorimeter. For the tests for observation of melting behavior using the cone calorimeter, a different sample assembly was utilized for the thermoplastic polymers, in which fire-resistant glass dishes with sizes of $100 \mathrm{~mm}$ in diameter and $15 \mathrm{~mm}$ in height were used holding the polymer samples to prevent the melting layer from spreading. In this case the sample sizes were $98 \mathrm{~mm}$ x $10 \mathrm{~mm}$ (diameter $\mathrm{x}$ thickness). The melting tests were also conducted at heat flux level of $50 \mathrm{~kW} / \mathrm{m}^{2}$.

\section{RESULTS AND DISCUSSION}

\section{Melting Behavior of the Polymers Exposed to Fire}

Most polymers tend to melt to a certain extent when being exposed to fires. This melting behavior varies considerably between different polymers. Some polymers melt significantly while others may melt slightly during burning. The resulted melt may be a 
thick liquid or a thin liquid pool. All these differences affect burning behavior of polymers significantly. In the present work, the melting behavior of a number of polymers was studied. It was found that for the polymers studied, the PP, LDPE, PA6 and EVA-18 melted considerably, while the PMMA melted but the resulting melt volatilized rapidly and therefore not much melt was observed. On the other hand, epoxy resin and phenolic resin were charring during burning with the epoxy resin producing some thin liquid-like melt. The photographs for melting behaviors of the polymers at the early stage of burning in the cone calorimeter are shown in Fig. 1 respectively for the PP, LDPE, EVA-18, PA6, PMMA, epoxy resin and phenolic resin. The differences in the melting behavior can be identified for these polymers, with the PP, LDPE, EVA-18 and PA6 significantly melting and forming a thick melt layer while the PMMA bubbling, rapidly volatilizing and burning at the surface, leaving little melt observed. By contrast to the above thermoplastics, however, the epoxy resin charred and was accompanied by a relatively small amount of thin liquid melt at the surface while the phenolic resin charred significantly and produced almost no melt. The characteristics of the melting layer as well as time to occurrence of melting and time to ignition recorded are summarized in Table 1.

Table 1. Characteristics of melting layer and time to melting and time to ignition for the polymers tested.

\begin{tabular}{|l|c|c|l|}
\hline Materials & $\begin{array}{c}\text { Time to melting } \\
\text { (s) }\end{array}$ & $\begin{array}{c}\text { Time to ignition } \\
\text { (s) }\end{array}$ & \multicolumn{1}{|c|}{$\begin{array}{c}\text { Melting layer } \\
\text { characteristics }\end{array}$} \\
\hline PP & 48 & 61 & thick melt \\
\hline LDPE & 82 & 90 & thick melt \\
\hline EVA-18 & 44 & 50 & thick melt \\
\hline PA6 & 67 & 109 & thick melt \\
\hline PMMA & - & 70 & bubbling with little melt \\
\hline Epoxy & - & 37 & $\begin{array}{l}\text { some thin melt after } \\
\text { ignition }\end{array}$ \\
\hline Phenolic & - & 45 & no melt \\
\hline
\end{tabular}

As demonstrated in Fig. 1, the melting behavior of these polymers is significantly different, although some basic patterns may be identified as: significantly melting, slightly melting with rapidly volatilizing, and slightly melting with significantly charring. Obviously, the PP, LDPE, EVA-18 and PA6 are in the first group, the PMMA belongs in the second group and two resins fall in the third group. It is important to note that the melting behavior influences the burning behavior of polymers. It was reported previously by Zhang et al [7] that the melting behavior of PP and PMMA polymer sheets installed in a vertical orientation exhibited distinct differences and resulted in a significant difference in flame spread rates, with the PMMA sheet having much higher rates than the PP sheet when subjected to the ignition source of number seven as defined in BS5852 1990 [8]. The burning and melting behaviors for the PMMA and PP sheets are compared in Fig. 2 Clearly, in this configuration, the PMMA sheet has not been observed for melting while the PP sheet melts significantly and forms a pool fire at the bottom. The two polymer sheets in these experiments have the same sizes of $800 \mathrm{~mm}$ x $2200 \mathrm{~mm}$ x $3 \mathrm{~mm}$ (width x height $x$ thickness). 

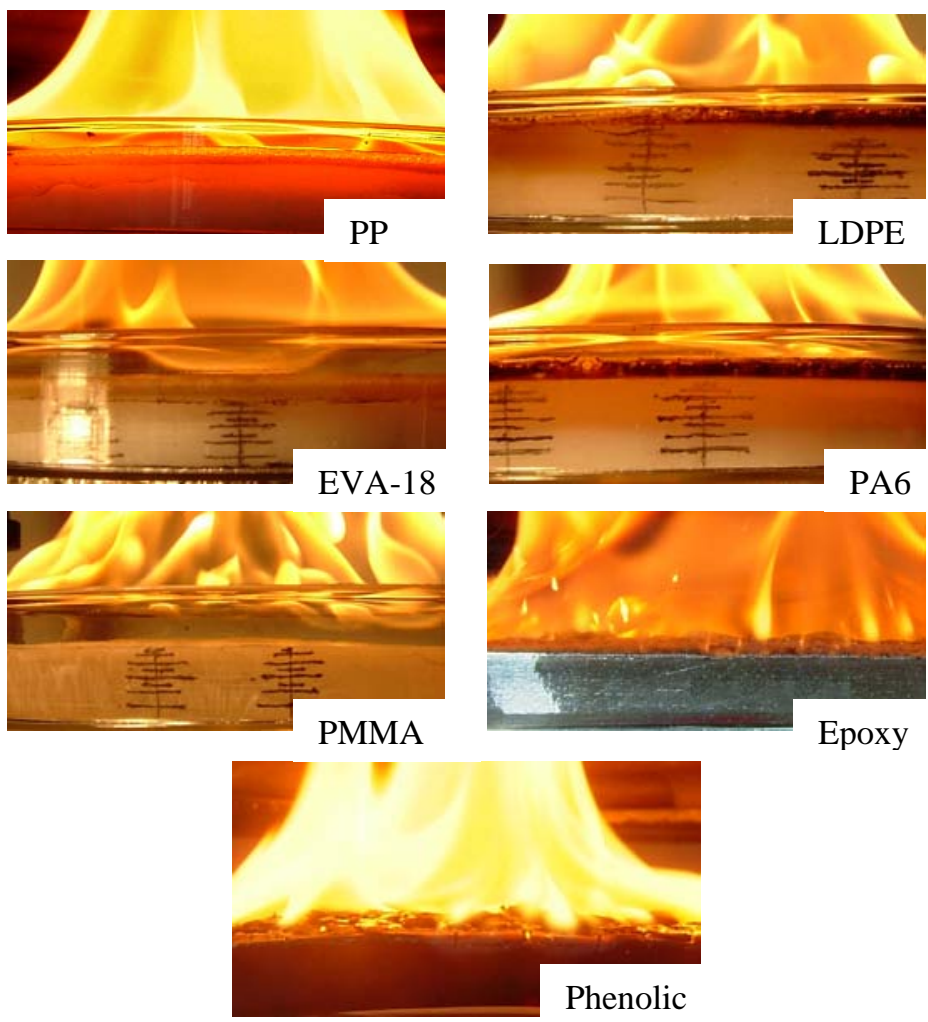

Fig. 1. Melting behaviors of different polymers during cone calorimeter tests at heat flux level of $50 \mathrm{~kW} / \mathrm{m}^{2}$.

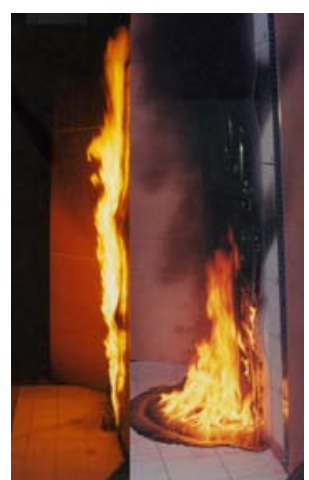

Fig. 2. Melting behaviors of PMMA (left) and PP (right) sheets installed in vertical orientation in large scale burn tests.

Interestingly, in a much smaller scale of fire test, i.e., the cone calorimeter test, with the samples installed in horizontal orientation, it was found that the melting behavior affected the mass loss rates of the thermoplastics studied during burning. Comparing the polymers that melted significantly, such as the PP, LDPE, EVA-18 and PA6 used in this study, with the PMMA undergoing rapid volatilization, their mass loss rates are considerably 
different as shown in Fig. 3. It can be seen that during the steady state stage of burning the former show lower mass loss rates than the latter. The melting behavior of polymers was a direct consequence of breakdown of macromolecular chains at higher temperatures when the polymers were exposed to fires. The melt formed consists of shorten chains but still not short enough to be volatile. This can be related to the pyrolysis process and mechanism of each individual polymer. A random pyrolysis process would be more likely to result in larger molecular fragments rather than low molecular weight monomers. This means that the macromolecular chains undergo gradual breakdown, resulting in a gradual reduction in molecular weight rather than rapid volatilization and therefore the rapid mass loss in which much smaller molecular fragments are produced, such as monomers. The pyrolysis processes for the PP, LDPE, EVA-18 and PA6 are more likely to be undergoing such a mechanism and therefore result in considerable melting but lower mass loss rates. However, it is believed that the pyrolysis process of PMMA is dominated by the depolymerization mechanism [1] and therefore it shows higher mass loss rates but less molecular weight reduction, therefore less melting. Moreover, for polymer chains to volatilize, depolymerization generally needs less energy input than a random pyrolysis process does due to the unzipping effect. Therefore, at the same external heat flux levels, the mass loss rates of the PMMA were much higher than those of the PP, LDPE, EVA-18 and PA6 as shown in Fig. 3. It indicates that in a real fire, the polymers decomposing by depolymerization would contribute greater in fire development than those with a random pyrolysis process.

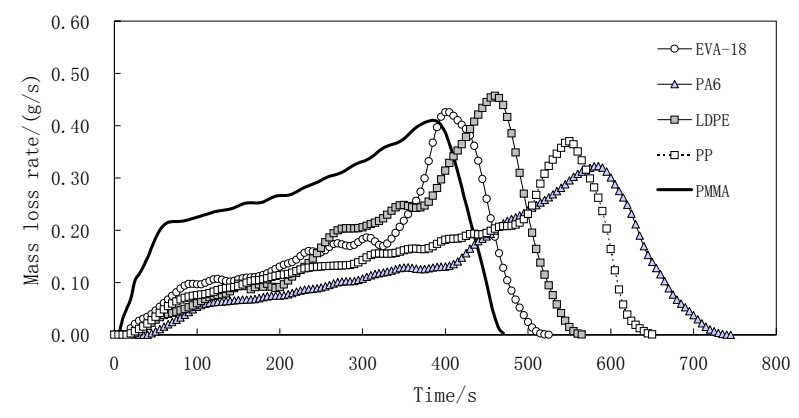

Fig. 3. Effects of melting behavior on the mass loss rates of polymers at $50 \mathrm{~kW} / \mathrm{m}^{2}$.

\section{MODELING THE BURNING RATE OF MELTING POLYMERS}

\section{Physical Description of Melting Model}

As shown above, for a melting polymer, the polymer can be divided into two layers during burning, i.e., the melting layer at the upper surface exposed to fire and the solid layer covered by the melting layer. It was reported that for some polymers specific heat $[9,10]$ and thermal conductivity [10] increased with increasing temperatures. Thus, the thermal properties in the two different phases are assumed to be different and the temperature gradient in the melt phase would be lower than that in the solid layer.

A physical description of this two-phase model is shown in Fig. 4. The proposed model is based on a number of assumptions: (1) once the surface temperature reaches the pyrolysis temperature $T_{p}$, the pyrolysed products will immediately volatilize and be ignited by the 
ignition source, i.e., the ignition temperature $T_{\text {ig }}$ is assumed to be same as the pyrolysis temperature $T_{p}$; (2) the pyrolysis process only takes place at the upper layer and there will be no mass transportation within the polymer; (3) the thickness of the interface layer between the melt and the solid phases is zero while in each phase the thermal property parameters are constant; (4) only one dimensional heat transfer is considered, except the upper surface the other sides are treated as insulated, and the effect of the flame is ignored.
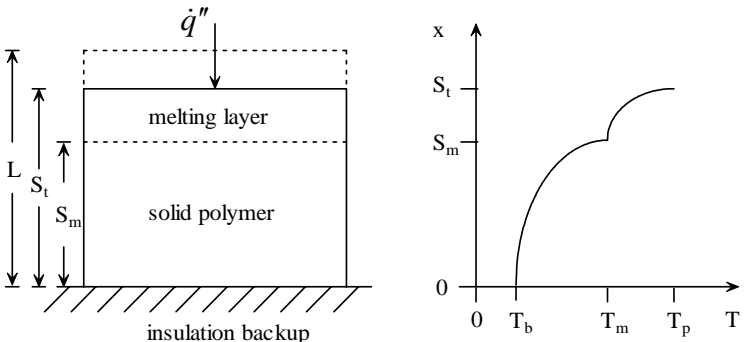

Fig. 4. Physical model of melting polymer during burning.

\section{The Mathematical Formulation of the Model}

Based on the above assumptions, the mathematical formulations can be drawn as follows:

Before the melting occurs, the heat conduction in the polymer is governed by

$\frac{\partial T}{\partial t}=\frac{k}{\rho c} \frac{\partial^{2} T}{\partial x^{2}}$

subjected to the initial conditions and boundary conditions:

$\left.T\right|_{t=0}=T_{\infty}$

$\left.k \frac{\partial T}{\partial x}\right|_{X=L}=\varepsilon \dot{q}_{e}^{\prime \prime}-\varepsilon \sigma\left(T_{s}^{4}-T_{\infty}^{4}\right)-h\left(T_{s}-T_{\infty}\right)$

$\left.k \frac{\partial T}{\partial x}\right|_{x=0}=0$

where $T$ is temperature distribution in the polymer, $T_{s}$ the surface temperature, $T_{\infty}$ the environment temperature, $k$ thermal conductivity, $\rho$ density, $c$ specific heat, $\varepsilon$ emissivity, $\sigma$ Stefan-Boltzmann constant, and $\dot{q}_{e}^{\prime \prime}$ external heat flux.

(a) After the polymer starts to melt, for the upper layer $\left(S_{m} \leq x \leq S_{t}\right)$

The heat conduction in the melt is governed by: 
$\frac{\partial T}{\partial t}=\frac{k_{m}}{\rho c_{m}} \frac{\partial^{2} T}{\partial x^{2}}$

subjected to the boundary conditions:

$\left.T\right|_{X=S_{m}}=T_{m}$

When $t<t_{\text {ig }}$

$\left.k_{m} \frac{\partial T}{\partial x}\right|_{x=S_{t}}=\varepsilon \dot{q}_{e}^{\prime \prime}-\varepsilon \sigma\left(T_{s}^{4}-T_{\infty}^{4}\right)-h\left(T_{s}-T_{\infty}\right)$

When $t \geq t_{\text {ig }}$

$\left.T\right|_{\chi=S_{t}}=T_{p}$

$\varepsilon \dot{q}_{e}^{\prime \prime}-\varepsilon \sigma\left(T_{p}^{4}-T_{\infty}^{4}\right)-h\left(T_{p}-T_{\infty}\right)=\left.k_{m} \frac{\partial T}{\partial x}\right|_{x=S_{t}}-\rho Q \frac{d S_{t}}{d t}$

(b) For the solid polymer layer $\left(0 \leq x \leq S_{m}\right)$

The heat conduction in the solid phase is governed by Eq. 1, subjected to the boundary conditions of Eqs. 6 and 4.

(c) At the interface between the melt and solid

$\left.k_{m} \frac{\partial T}{\partial x}\right|_{x=S_{m}}-k \frac{\partial T}{\partial x} \mid=-\rho\left(c_{m}-c\right) T_{m} \frac{d S_{m}}{d t}$

After being ignited, the mass flux will be

$\dot{m}^{\prime \prime}=-\rho \frac{d S_{t}}{d t}$

By a differential treatment of the above equations and descretization, the above equations can be solved numerically using a computer. The temperature distributions at time $t$ can be obtained and then the surface location can be determined by Eq. 9, the interface location can be determined by Eq. 10, and the mass loss rate can be calculated through Eq. 11 with the sample area being taken into account. 


\section{Validation of the Model}

The simulation results using the model in which the melting layer was included were generally closer to the experimental results obtained from the cone calorimeter tests. Figure 5 shows the comparison between the simulations with and without melting layers and the experimental results from the cone calorimeter test respectively for the PP, LDPE, EVA-18, PA6 and PMMA. The parameters used for solid phase and melting phase are listed in Table 2 for the above polymers.
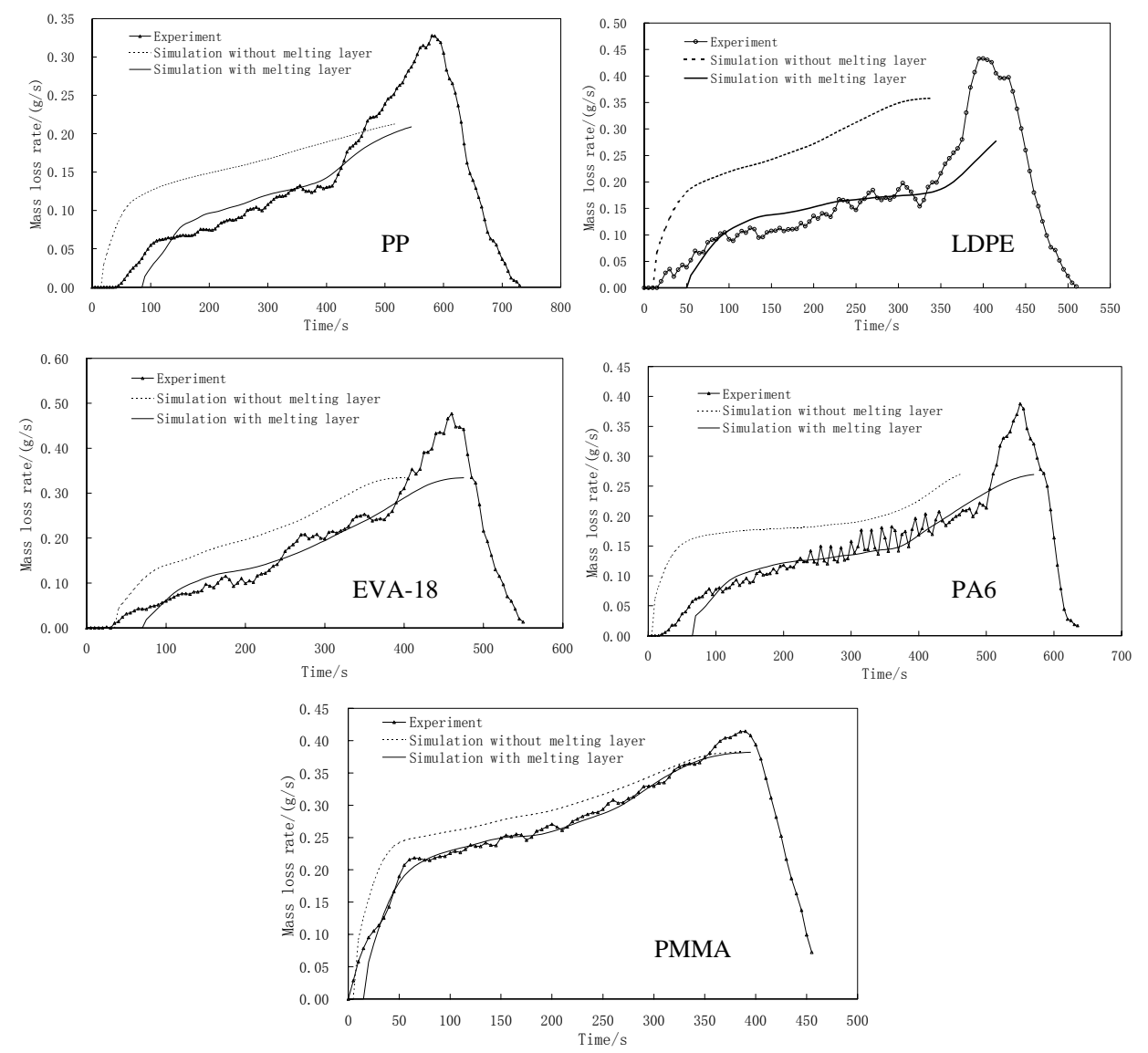

Fig.5. The comparisons between simulated and experimental results of mass loss rates for the PP, LDPE, EVA-18, PA6 and PMMA polymers at heat flux level of $50 \mathrm{~kW} / \mathrm{m}^{2}$. 
Table 2. The property parameters of the polymers used in the modeling.

\begin{tabular}{|l|l|l|l|l|l|l|l|l|}
\hline & $\rho^{\mathrm{a}}$ & $k^{\mathrm{b}}$ & $k_{m}{ }^{\mathrm{c}}$ & $c^{\mathrm{b}}$ & $c_{m}{ }^{\mathrm{c}}$ & $T_{p}{ }^{\mathrm{d}}$ & $T_{m}{ }^{\mathrm{e}}$ & $Q$ \\
$\mathrm{~K}$ & $\mathrm{~K} /(\mathrm{mK})$ & $\mathrm{J} /(\mathrm{kgK})$ & $\mathrm{J} /(\mathrm{kgK})$ & $\mathrm{K}$ & $\mathrm{K}$ \\
\hline PP & 905 & 0.12 & 0.50 & 2350 & 3200 & 610 & 450 & 1.3 \\
\hline LDPE & 802 & 0.33 & 0.45 & 2300 & 2900 & 640 & 400 & 1.0 \\
\hline EVA-18 & 900 & 0.25 & 0.38 & 1500 & 2700 & 600 & 400 & 1.0 \\
\hline PA6 & 1095 & 0.22 & 0.75 & 1675 & 2400 & 615 & 500 & 1.6 \\
\hline PMMA & 1180 & 0.21 & 0.42 & 1400 & 1600 & 550 & 450 & 1.0 \\
\hline
\end{tabular}

${ }^{\mathrm{a}}$ measured in the study; ${ }^{\mathrm{b}}$ from Ref. [9]; ${ }^{\mathrm{c}}$ estimated; ${ }^{\mathrm{d}}$ from Ref. [1]; ${ }^{\mathrm{e}}$ from Ref. [11]

From the comparisons, it can be seen that the prediction model which has been modified by taking the melting behavior of polymers into account, generally improves the predicted results when compared with the cone calorimeter experimental results.

\section{SUMMARIES}

The melting behavior of a number of polymers has been studied experimentally with the cone calorimeter. The results show that some thermoplastic polymers like the PP, LDPE, EVA-18, PA6 melted significantly while the PMMA showed much less melting. Moreover, the melting behavior of these polymers affected their mass loss rates during the steady state burning stage. It was found that for the thermoplastic polymers used in this study intensive melting was likely to reduce the mass loss rates during the steady burning stage. Meanwhile, a numeric model for polymer burning was developed to include the melting behavior. The modeling results were validated against the cone calorimeter experimental data. The results showed that the modeling prediction was in fair agreement with the experimental results when a melting layer was included in the model.

\section{ACKNOWLEDGEMENT}

The authors gratefully acknowledge the financial support of the China NKBRSF project (No. 2001CB409600) and the China NSFC Funds (No. 50176021).

\section{REFERENCES}

[1] Beyler, C., "Thermal Decomposition of Polymers," The SFPE Handbook of Fire Protection Engineering ( $1^{\text {st }}$ ed.), DiNenno, P. J. (ed.), National Fire Protection Association, Quincy, MA 02269, 1988, pp. 1/173-176.

[2] Quintiere, J., and Iqbal, N., "An Approximate Integral Model for the Burning Rate of a Thermoplastic-like Material,” Fire and Materials, 18: pp. 89-98, (1994).

[3] Steckler, K.D., Kashiwagi, T., Baum, H.R., and Kanemaru, K., “Analytical Model for Transient Gasification of Noncharring Thermoplastic Materials,” The Proceedings of the $3^{\text {rd }}$ IAFSS Conference, International Association for Fire Safety Science, 1991, pp. 895-904.

[4] Moghtaderi, B., Novozhilov, V., Fletcher, D., and Kent, J.H., "An Integral Model for the Transient Pyrolysis of Solid Materials," Fire and Materials, 21: pp. 7-16, (1997). 
[5] Staggs, J.E.J., and Whiteley, R., "Modeling the Combustion of Solid-phase Fuels in Cone Calorimeter Experiments," Fire and Materials, 23: pp. 63-69, (1999).

[6] Zhang, J., Shields, T.J., and Silcock, G.W.H., "Fire Hazard Assessment of Polypropylene Wall Linings Subjected to Small Ignition Sources,” Journal of Fire Sciences, 14: pp. 67-84, (1996).

[7] Zhang, J., Shields, T.J., and Silcock, G.W.H., "Effect of Melting Behavior on Upward Flame Spread of Thermoplastics," Fire and Materials, 21: pp. 1-6, (1997).

[8] BS 5852-1990, "Methods of Test for Assessment of the Ignitability of Upholsterd Seating by Smouldering and Flaming Ignition Sources,” British Standards Institution, London, 1990.

[9] Thompson, E.V., "Thermal Properties," Encyclopedia of Polymer Science and Engineering, Vol. 16, Mark, H.F. (ed.), John Wiley \& Sons, New York, 1989, pp. 711-747.

[10] Chartoff, R.C., “Thermoplastic Polymers," Thermal Characterization of Polymeric Materials ( $2^{\text {nd }}$ ed.), Turi, E. A. (ed.), Academic Press, New York, 1997, pp. 621-625.

[11] Sun, S.C., Handbook of Plastics, Zhejiang Science and Technology Publisher, Hangzhou, 1999, p. 54. 